\title{
Growth and proliferation in mouse parietal yolk sac during whole embryo culture
}

\author{
D. L. Cockroft \\ Imperial Cancer Research Fund, Developmental Biology Unit, Department of Zoology, \\ South Parks Road, Oxford OX1 3PS, U.K.
}

\begin{abstract}
Summary. Use of the culture techniques for postimplantation rodent embryos, modified by explanting Day 9 or Day 10 embryos with the trophoblast cells removed but the remainder of the parietal yolk sac left intact, resulted in significant expansion of Reichert's membrane, accompanied by a marked increase in the numbers of the adherent parietal endoderm cells which synthesize the membrane. The surface area of the parietal endoderm/Reichert's membrane complex roughly doubled during culture, and the combined protein content of the cells and their basement membrane was also raised after incubation. Parietal endoderm cell numbers, calculated from area and cell density measurements on flattened membranes, increased by $54-190 \%$, depending on the age of the embryo.
\end{abstract}

\section{Introduction}

The parietal yolk sac of the mid-gestation mouse fetus consists of a parietal endoderm and a trophoblast layer, with Reichert's membrane in between. It surrounds the conceptus and is closely apposed to the visceral yolk sac which is internal to it. The tissue has been studied mainly as a convenient system for investigating basement membrane synthesis (Minor et al., 1976a, b; Hogan, 1980; Hogan et al., 1980). Although in conventional histological preparations parietal endoderm cells appear to be similar to each other, it has been shown by scanning electron microscopy and other means that there are striking regional and temporal variations in the morphology of the cells, and time-lapse video recordings of whole mount preparations in tissue culture have shown that the motile activity of the cells depends on their position and the age of the embryo (Cockroft, 1986). The above studies demonstrated that parietal endoderm cells on their basement membrane survive for prolonged periods in culture, and that they continue to synthesize basement membrane, but there has been no previous unequivocal evidence that parietal endoderm cell numbers increase in vitro. Normal relations between the parietal and visceral endoderm cells could be important for such proliferation to happen, and so the present study was undertaken using a modified whole embryo culture technique (New, 1978). It has previously been shown that some expansion of the rat parietal yolk sac in vitro can be achieved by use of a higher than normal oxygen concentration, and with dilution of the culture serum (Ellington \& New, 1980).

\section{Materials and Methods}

The mice used were of the P.O. (Pathology Oxford) strain, and they were killed by cervical dislocation on Day 9 or Day 10 of pregnancy, Day 1 being that on which a vaginal plug was observed. The uteri were torn open in phosphatebuffered saline (PBS) and the conceptuses removed and transferred to PB1 medium (Whittingham \& Wales, 1969), modified by the inclusion of glucose $(1 \mathrm{~g} / 1)$ instead of lactate, and fetal calf serum $(10 \% \mathrm{v} / \mathrm{v})$ in place of bovine serum albumin. Explantation was completed as described by New (1971), except that, for embryos to be cultured with intact Reichert's membrane, the trophoblast was carefully peeled off leaving Reichert's membrane, with its internally adherent parietal endoderm cells, as an intact layer overlying the visceral yolk sac. For some embryos, however, 
Reichert's membrane was torn open, exposing the visceral yolk sac to the medium. The maximum and minimum diameters of the visceral yolk sac or of the parietal endoderm/Reichert's membrane complex for each embryo were measured before culture. (Because the parietal and visceral yolk sacs are closely apposed to each other, and the outermost (parictal) layer is very thin, the surface areas of the two membranes are virtually identical in a particular specimen, and so the measurements may be used interchangeably.) The surface areas of the parietal endoderm/ Reichert's membrane or of the visceral yolk sac were calculated using the formula $\pi a b$, where $a$ and $b$ are respectively the maximum and minimum diameters of the membranes.

Two embryos with an intact Reichert's membrane and two with it open were placed in each culture vessel, a 50-ml polypropylene centrifuge tube (Falcon; Beckton Dickinson, Oxford, U.K. or Costar; L. H. Engineering Co., Stoke Poges, Bucks, U.K.) containing $5 \mathrm{ml}$ pure rat serum prepared by centrifugation immediately after withdrawal from the donor animal, and heat-inactivated $\left(30 \mathrm{~min}\right.$ at $56^{\circ} \mathrm{C}$ ) and gassed before use (Steele \& New, 1974; New et al., 1976). Day-9 embryos were gassed initially with $10 \% \mathrm{O}_{2} / 5 \% \mathrm{CO}_{2} / 85 \% \mathrm{~N}_{2}$, which was changed to $20 \% \mathrm{O}_{2} / 5 \% \mathrm{CO} / 75 \%$ $\mathrm{N}_{2}$ after $18 \mathrm{~h}$ of culture. Day-10 embryos were gassed with $10,20,40$ or $95 \% \mathrm{O}_{2}$ throughout culture, each with $5 \%$ $\mathrm{CO}_{2}$, and $\mathrm{N}_{2}$ to make up the balance (if any). At the end of the culture period, which was $17 \mathrm{~h} \mathrm{for} \mathrm{Day-10} \mathrm{embryos,} \mathrm{or}$ $30 \mathrm{~h}$ for Day-9 embryos, heart beats and visceral yolk sac blood circulations were recorded and the yolk sac dimensions were measured again. After removal of the extraembryonic membranes, somite counts were made and crown-rump lengths were measured. In some instances protein contents of the embryos and of the parietal endoderm/ Reichert's membrane were determined by the method of Lowry et al. (1951).

To confirm that cell proliferation was taking place during culture, the number of parietal endoderm cells on the membranes of cultured and uncultured embryos was determined by measuring the areas of the membranes and estimating cell densities. To do this, the entire conceptus with intact Reichert's membrane was fixed for 10 min in formal saline at room temperature, the Reichert's membrane (with adherent parietal endoderm cells) was removed and cuts were made in it to allow it to be spread out substantially flat on a microscope slide and mounted in Aquamount (BDH; Poole, Dorset, U.K.). The outline of the membrane was traced using a drawing tube attached to a Wild M5 dissecting microscope, and cell counts on four fields, each of $30276 \mu \mathrm{m}^{2}$, were made for each membrane, using a drawing tube attached to a Zeiss RA microscope. Thus it was possible to estimate the cell density and the total number of cells on each membrane.

\section{Results}

Representative embryos explanted on Day 10 are illustrated in Fig. 1. Development of such embryos was marginally better in $40 \% \mathrm{O}_{2}$ than in $20 \% \mathrm{O}_{2}$, and considerably better than in $10 \% \mathrm{O}_{2}$ (Table 1). Increase in the surface area of Reichert's membrane was similar with all three oxygen concentrations, at $86-88 \%$, compared with an increase of up to $112 \%$ in the visceral yolk sacs of

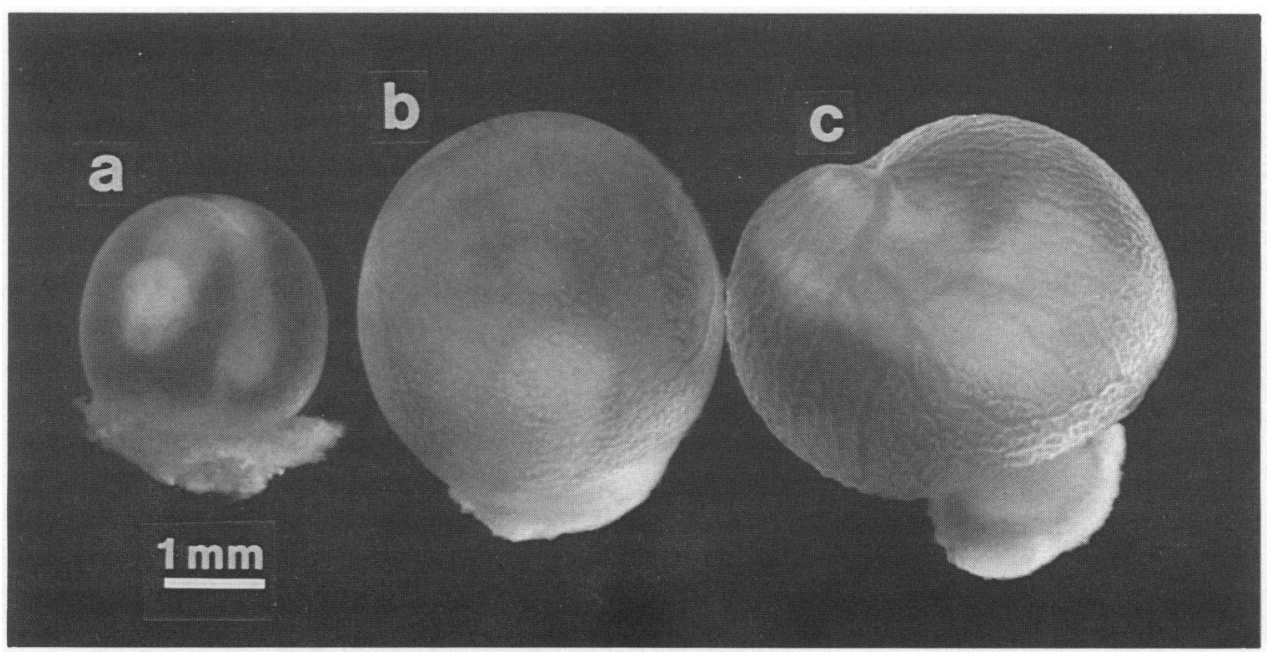

Fig. 1. Day-10 mouse embryos: (a) at explantation, (b) after $17 \mathrm{~h}$ culture with an intact parietal endoderm/Reichert's membrane, and (c) after $17 \mathrm{~h}$ culture with Reichert's membrane opened. Considerable expansion of the intact Reichert's membrane has taken place, but not quite as much as of the visceral yolk sac of the embryo in which it was opened. 


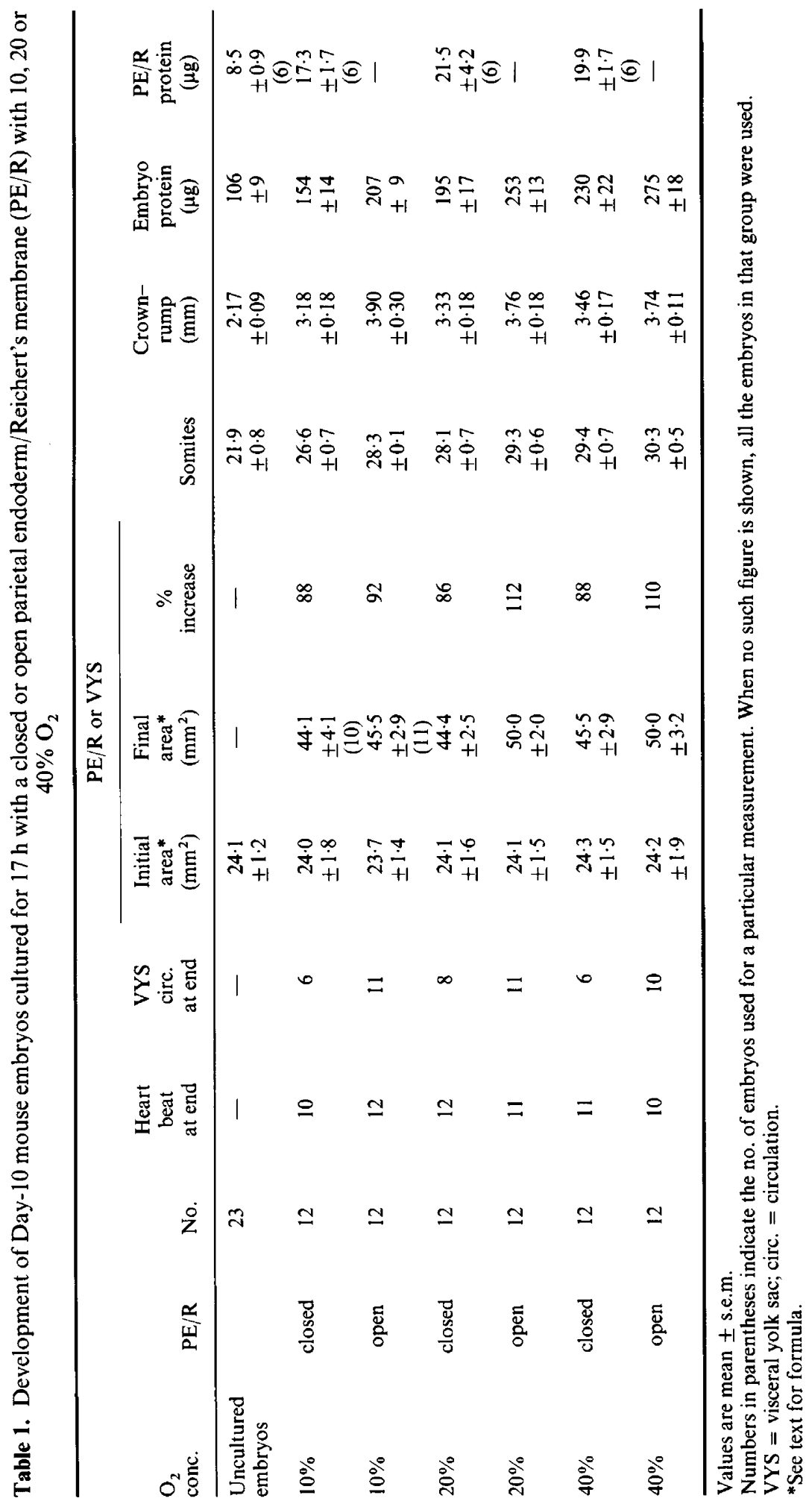


Table 2. Estimates of cell numbers in the parietal endoderm/Reichert's membrane (PE/R) complex uncultured and $17 \mathrm{~h}$-cultured Day-10 mouse embryos

\begin{tabular}{|c|c|c|c|c|c|c|c|c|}
\hline \multirow[b]{2}{*}{$\begin{array}{l}\text { Oxygen } \\
\text { conc. } \\
\%\end{array}$} & \multirow[b]{2}{*}{ No. } & \multicolumn{3}{|c|}{$\mathrm{PE} / \mathrm{R}$} & \multirow[b]{2}{*}{$\begin{array}{l}\text { No. of PE } \\
\text { cells/ } \\
\text { membrane }\end{array}$} & \multirow[b]{2}{*}{$\begin{array}{c}\% \\
\text { increase }\end{array}$} & \multirow[b]{2}{*}{ Somites } & \multirow[b]{2}{*}{$\begin{array}{c}\text { Crown-rump } \\
\text { length } \\
(\mathrm{mm})\end{array}$} \\
\hline & & $\begin{array}{c}\text { Initial } \\
\text { area } \\
\left(\mathrm{mm}^{2}\right)\end{array}$ & $\begin{array}{l}\text { Final } \\
\text { area } \\
\left(\mathrm{mm}^{2}\right)\end{array}$ & $\begin{array}{c}\% \\
\text { increase }\end{array}$ & & & & \\
\hline $\begin{array}{l}\text { Uncultured } \\
\text { embryos }\end{array}$ & 6 & $29 \cdot 4 \pm 1 \cdot 5$ & - & - & $58800 \pm 3900$ & - & $25 \cdot 5 \pm 0 \cdot 3$ & $2.72 \pm 0.09$ \\
\hline 20 & 6 & $28.4 \pm 0.9$ & $51 \cdot 4 \pm 2 \cdot 2$ & 81 & $95000 \pm 6400$ & 62 & $31 \cdot 7 \pm 0.4$ & $3.93 \pm 0.05$ \\
\hline 40 & 6 & $28 \cdot 6 \pm 0.9$ & $53.2 \pm 1.5$ & 86 & $90700 \pm 5900$ & 54 & $32.5 \pm 1.0$ & $3 \cdot 87 \pm 0 \cdot 18$ \\
\hline
\end{tabular}

Values are mean \pm s.e.m.

embryos cultured with Reichert's membrane opened. There was also a significant increase, up to $2 \cdot 5$-fold, in the protein content of the parietal endoderm cells + Reichert's membrane, although this was marginally less in the embryos cultured with $10 \% \mathrm{O}_{2}$ than with higher oxygen concentrations. On average the parietal endoderm cell number in Day 10 embryos cultured with $20 \%$ or $40 \% \mathrm{O}_{2}$ increased by $62 \%(P<0.001)$ and $54 \%(P<0.002)$ respectively, compared with matched, uncultured controls (Table 2).

Because development at the highest oxygen concentration used was marginally better than with the lower oxygen tensions, a further series of experiments was done to compare development in $95 \% \mathrm{O}_{2}$ with that in $40 \% \mathrm{O}_{2}$ and $20 \% \mathrm{O}_{2}$. Also, because it was thought that the quantity of serum might be limiting development, only two embryos, one with an open and one with a closed Reichert's membrane, were placed in each culture tube, which contained $4 \mathrm{ml}$ serum. The results (Table 3) show that development with the lower oxygen concentrations is similar to that obtained previously, and with $95 \% \mathrm{O}_{2}$ it is inferior, but not markedly so, except for the protein content of the parietal endoderm/Reichert's membrane. The greatest expansion in the area of Reichert's membrane in this case was $101 \%$, obtained with $20 \% \mathrm{O}_{2}$, and so was almost as great as the visceral yolk sac expansion of the embryos cultured with open Reichert's membranes $(110 \%)$.

The results for Day-9 embryos are shown in Table 4. The embryos cultured for $30 \mathrm{~h}$ with intact parietal endoderm/Reichert's membrane showed an approximate doubling in surface area during culture, together with a 3 -fold increase in parietal endoderm cell number. However, although they maintained a heart beat and visceral yolk-sac circulation throughout culture, the embryos in these explants were obviously severely constricted by the extraembryonic membranes; there was much greater expansion of the visceral yolk sacs in the embryos of this age cultured with open Reichert's membrane.

\section{Discussion}

These results demonstrate that significant increases in parietal endoderm cell number take place in whole embryo culture, together with expansion of the underlying basement (Reichert's) membrane. For Day-10 embryos, the expansion of conceptuses with intact Reichert's membrane is almost as great as for those with it open, whereas Day-9 embryos expand far less with a closed than with an open Reichert's membrane, perhaps because of the longer culture period ( $30 \mathrm{~h}$ instead of $17 \mathrm{~h}$ ).

Although there have been no previous studies on the parietal yolk sac of the mouse in whole embryo culture, there is some pertinent work on the rat embryo. Payne \& Deuchar (1972) cultured rat embryos with the parietal yolk sac (including trophoblast cells) in place, and found higher embryonic protein contents and leucine incorporation than when these tissues were removed, 

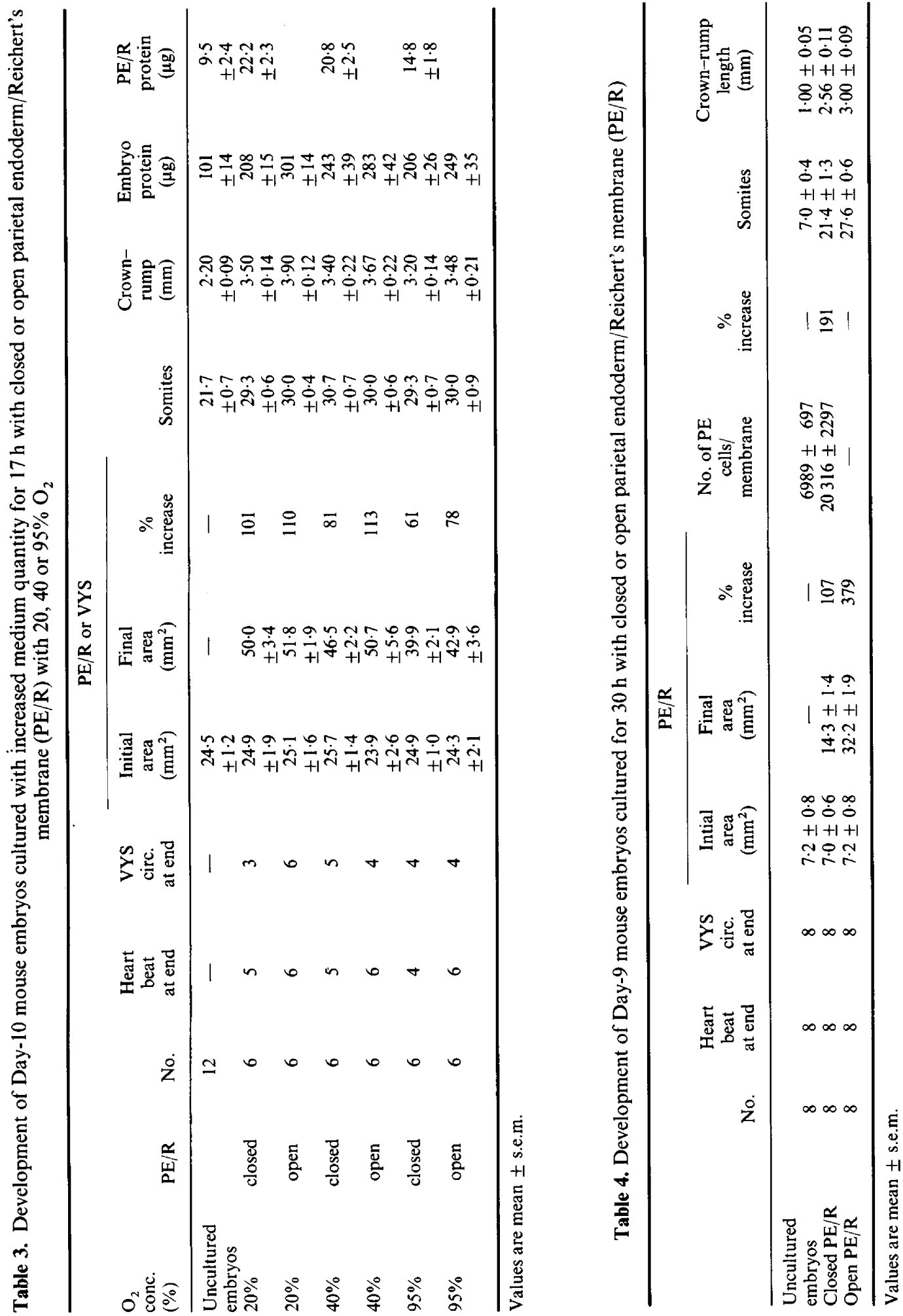
although the most normal morphology and expansion of the extraembryonic cavities were obtained under the latter conditions. However, in both cases development was poor compared with that previously obtained with embryos of similar age cultured under standard conditions (New et al., 1973). Ellington \& New (1980) cultured Day-11 rat embryos for $24 \mathrm{~h}$ with intact parietal yolk sacs (i.e. without removing the trophoblast). At best they obtained a $30 \%$ increase in yolk sac area, using $50 \%$ serum $/ 50 \%$ Hanks as the culture medium, and using a gas phase which increased from $20 \%$ to $95 \% \mathrm{O}_{2}$ during culture. Ellington \& New (1980) stated that only $25-35 \%$ of the surface of the conceptus was covered with trophoblast at explantation, and that the trophoblast extended to cover $50-75 \%$ of the surface by the end of culture. Presumably it was this thick trophoblast layer which necessitated such high oxygen concentrations and it may also have physically impeded expansion of the conceptus. In the mouse, the trophoblast forms a continuous sheet completely enveloping the conceptus at the stages studied in this paper, and early attempts to culture embryos with this layer intact met with no success, even at high oxygen tensions. Dilution of the serum was also found to be deleterious. However, with the trophoblast removed, the intact Reichert's membrane appears to offer little impediment to the passage of oxygen, and the optimum oxygen concentration with closed or open Reichert's membrane is quite similar (present study).

Very little is known about the normal differentiation and proliferation of the parietal endoderm in vivo. The apparent paucity of dividing cells in the tissue and the morphology of cells in the marginal zone between visceral and parietal layers has led to the suggestion that parietal cells are recruited from the visceral endoderm (Hogan \& Newman, 1984). Circumstantial evidence in favour of this hypothesis is the observation that, under experimental conditions, visceral endoderm cells can acquire a parietal phenotype and synthesize large amounts of laminin and type IV procollagen - proteins characteristic of Reichert's membrane (Hogan \& Tilly, 1981). Further evidence that visceral cells retain the ability to transform to the parietal type comes from blastocyst injection experiments (Gardner, 1982); injected Day-6 or Day-7 visceral endoderm cells contribute almost exclusively to the parietal endoderm in the resulting chimaeras. However, to obtain further information on the normal growth process in the parietal endoderm, it is desirable to have an in-vitro system such as the one described here, in which Reichert's membrane expands and the parietal endoderm cell numbers increase. Presumably the reason why such growth occurs in whole embryo culture, but not in cultures of the parietal endoderm/Reichert's membrane alone, is that the normal relations between visceral and parietal layers are important. The tension induced in Reichert's membrane by the expansion of the conceptus may also be significant; in cultures of parietal endoderm cells on isolated pinned-out Reichert's membrane, where expansion of the membrane does not take place, clumps of cells appear for which there is apparently no room on Reichert's membrane (Cockroft, 1986). The presence of the trophoblast does not appear to be necessary for growth and proliferation of the rest of the parietal yolk sac.

I thank Professor R. L. Gardner for encouragement and advice; Ms J. Green and $\mathrm{Mr} \mathrm{T}$. Davies for technical assistance; Mrs P. Hickey, Mrs J. Williamson and Mr A. Cogan for help in preparation of the manuscript; and the Imperial Cancer Research Fund for financial support.

\section{References}

Cockroft, D.L. (1986) Regional and temporal differences in the parietal endoderm of the midgestation mouse embryo. J. Anat. 145, 35-47.

Ellington, S.K.L. \& New, D.A.T. (1980) In-vitro development of the rat parietal yolk sac. J. Reprod. Fert. 60, 377-382.

Gardner, R.L. (1982) Investigation of cell lineage and differentiation in the extraembryonic endoderm of the mouse embryo. J. Embryol. exp. Morph. 68, 175-198.

Hogan, B.L.M. (1980) High molecular weight extracellular proteins synthesised by endoderm cells derived from mouse teratocarcinoma cells and normal extraembryonic membranes. Devl Biol. 76, 275-285. 
Hogan, B.L.M. \& Newman, R. (1984) A scanning electron microscope study of the extraembryonic endoderm of the 8 th-day mouse embryo. Differentiation 26, 138-143.

Hogan, B.L. \& Tilly, R. (1981) Cell interactions and endoderm differentiation in cultured mouse embryos. J. Embryol. exp. Morph. 62, 379-394.

Hogan, B.L.M., Cooper, A. \& Kurkinen, M. (1980) Incorporation into Reichert's membrane of lamininlike extracellular proteins synthesised by parietal endoderm cells of the mouse embryo. Devl Biol. 80, 289-300.

Lowry, O.H., Rosebrough, N.J., Farr, A.L. \& Randall, R.J. (1951) Protein measurement with the Folin phenol reagent. J. biol. Chem. 193, 265-275.

Minor, R.R., Hoch, P.S., Koszalka, T.R., Brent, R.L. \& Kefalides, N.A. (1976a) Organ cultures of the embryonic rat parietal yolk sac. I. Morphologic and autoradiographic studies of the deposition of the collagen and non-collagen glycoprotein components of basement membrane. Devl Biol. 48, 344-364.

Minor, R.R., Strause, E.L., Koszalka, T.R., Brent, R.L. \& Kefalides, N.A. (1976a) Organ cultures of the embryonic rat parietal yolk sac. II. Synthesis, accumulation and turnover of collagen and noncollagen basement membrane glycoproteins. Devl Biol. 48, 365-376.
New, D.A.T. (1971) Methods for the culture of postimplantation rodents. In Methods in Mammalian Embryology, pp. 305-319. Ed. J. C. Daniel. W.H. Freeman \& Co., San Francisco.

New, D.A.T. (1978) Whole-embryo culture and the study of mammalian embryos during organogenesis. Biol. Rev. 53, 81-122.

New, D.A.T., Coppola, P.T. \& Terry, S. (1973) Culture of explanted rat embryos in rotating tubes. $J$. Reprod. Fert. 35, 135-138.

New, D.A.T., Coppola, P.T. \& Cockroft, D.L. (1976) Improved development of head-fold rat embryos in culture resulting from low oxygen and modifications of the culture serum. J. Reprod. Fert. 48, 219-222.

Payne, G.S. \& Deuchar, E.M. (1972) An in vitro study of functions of embryonic membranes in the rat. $J$. Embryol. exp. Morph. 27, 533-542.

Steele, C.E. \& New, D.A.T. (1974) Serum variants causing the formation of double hearts and other abnormalities in explanted rat embryos. J. Embryol. exp. Morph. 31, 709-719.

Whittingham, D.G. \& Wales, R.G. (1969) Storage of twocell mouse embryos in vitro. Aust. J. biol. Sci. 22, 1065-1068.

Received 22 April 1987 